\title{
Personality Development Theory and Its Enlightenments to the Children's Education
}

\author{
Dan Li \\ School of Education and Sports, Bohai University, Jinzhou, 121013, China \\ 123581094@qq.com
}

\begin{abstract}
Keywords: personality development theory; children's education; enlightenment; cognitive development theory
\end{abstract}

\begin{abstract}
Children are the future of our motherland, is the hope of the Chinese nation. Children's education is the important foundation of the education career, plays an important task for the future. Personality development theory as the theoretical basis is provided for children's education and guidance method, based on Freud's theory of personality development phase, Piaget's theory of cognitive development and eight stages of Erikson's personality development theory as the foundation, proposed the theory of personality development of children education enlightenment: children at all ages have different education, children's education mainly eventually point is "self-identity", the harmonious family atmosphere conducive to children's healthy growth plays an important role in children's education, mother and father is indispensable role in the process of children's education, reward and punishment is a powerful means to promote the development of children.
\end{abstract}

\section{Introduction}

Children education is about the cultivation and training of the moral education, intellectual education and sports, and etc. is the important link of improving the quality of the population. Puberty arrives before the age of known as children or young, they in such aspects as ideology, personality, intelligence and physique of plastic children's educational is very strong. Children's education is the important foundation of the whole education career. Children the importance of education embodied in the following aspects: one is that children's education to promote the brain developed, especially for left and right brain development in parallel. Don't let the child grew up naturally, passively waiting for the child brain mature later re-education, it hardly conducive to children in the developing brain to form the most efficient brain function network; Second, children's education development and huge potential, this potential can only be more fully the development in infants and young children period, or will be buried. A variety of potential is only likely to be more fully stimulate brain are developing; Three is, 0 to 6 years old, is the optimal period and extend to 12 times ritual education, optimal period education work half one hundred times. Many aspects and miss the optimal period education is wasted effort, even in vain; Four it is to cultivate the children's character in the first place, it is an important factor to give children a lifetime of happiness and success; Fifth is that children to observe, question, or the creation of hands and brain, education will grab since childhood. Develop a discovery, invention and creative talent, must be sure to lead to observe, to ask questions since childhood, thinking, discussion and hands-on operation.

Personality is unique to humans, obtained by congenital genetic quality and environment formed by the interaction between the day after tomorrow, may represent the nature of human soul and personality traits of character, temperament, character, quality, faith and conscience, and the formation of the dignity and charm, etc. Personality development theory as the theoretical basis is provided for children's education and guidance method, contributes to an understanding of the psychological development of children, to grasp the key period of children grow up, in view of the possible problems, take active coping strategies, nip in the bud, realize the children happy and healthy growth, become a useful person to society in the future. 


\section{Basics of Personality Development Theory}

Personality development theory is a theory of anthropology, western psychologists argue a lot, but from the perspective of their own point of view to make a clear description. Three of the most famous theory is: the session with Sigmund Freud's theory of personality development stage, Jean Piaget's theory of cognitive development, e. h. Erikson's theory of personality development eight stages.

(1) Session with Sigmund Freud's personality development theory. Sigmund Freud was the famous Austrian, doctors and psychologists the founder of psychoanalysis. He brings the study of psychology into the deep spiritual world, for the modern psychology show a brand new field. Freud's personality theory mainly includes the content of the personality structure and personality development motivation, personality, adaptation and personality development stage. Freud thinks that personality development is the basic power of instinct, especially sexual instinct, sexual instinct is driven by people all the behavior of the original power. In each stage of the personality development, will have a special area to become the center of the libido excitement and satisfaction. Freud depending on the libido excited area could be divided into five stages of personality development, as shown in Fig. 1. Freud in the process of research of personality development, pay attention to the psychological development stage, different stage of physiological basis and the role of education and training in each stage of development. The division of his five stages of psychological development and psychological age phase of the science division of consistency. Emphasizes that the early experiences in the important role of personality development, think the child is father of the man, think personality disorder is one of the causes of the early experiences of psychological mark or trauma.

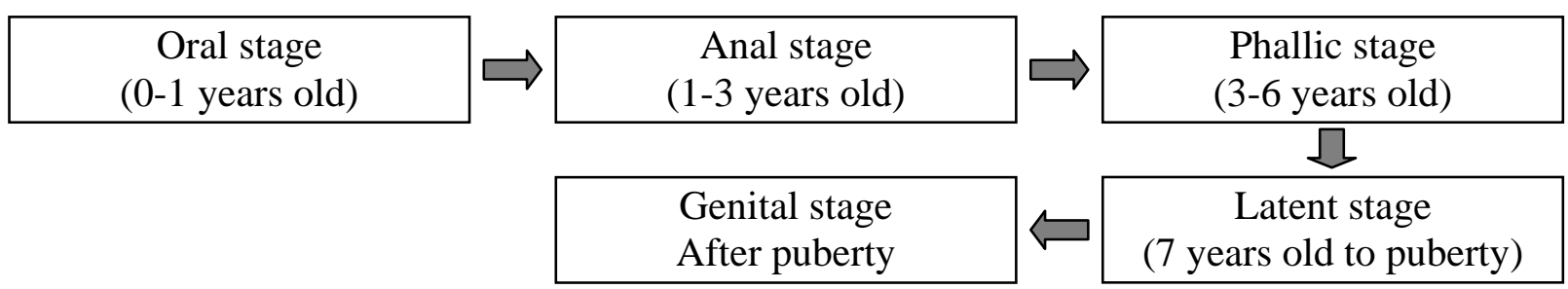

Fig. 1. Stage theory of personality development of Sigmund Freud

(2) Jean Piaget's the cognitive development theory. Jean Piaget was one of the most famous child psychologists, in modern to Freud the kind of casual and lack of systemic clinical observation, into a more scientific and systematic, cognitive development theory has become the model of the discipline. Cognitive development refers to the individual since birth in adapt to the environment, the cognition of things and the way of thinking when facing the problem situation and ability, along with the age growth and change. Piaget will influence children's psychological development of various factors are analyzed, and the induction of mature, experience, four basic factors such as social environment and balance. The cognitive development as the development of cognitive structure, based on cognitive structure to distinguish the psychological development stage, the cognitive development is divided into four phases, as shown in Fig. 2. Piaget's theory of cognitive development out of genetic and environmental arguments and entanglements, explicitly put forward the development of internal and external interaction, namely the psychological development is the result of the subject and object interaction.

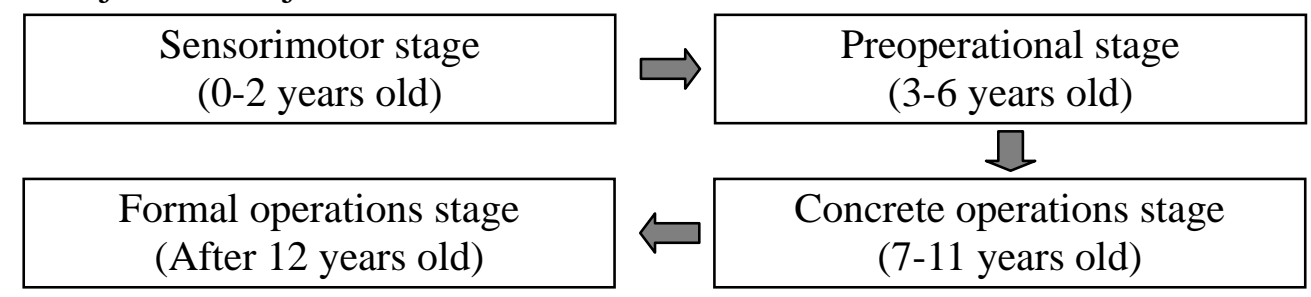

Fig. 2. Cognitive-developmental theory of Jean Piaget

(3) E. H. Erikson's theory of personality development eight stages. He is a famous American 
psychiatrist, the representative figure of new psychoanalysis pie. He thinks, the person's selfconsciousness development for life, the formation and development process of the ego is divided into eight stages, as shown in figure 3.The eight stages of order is determined by heredity, but each stage can navigate is determined by the environment, so the theory can be called psychological social stage theory, every stage is not to be ignored. Erikson theory provides a theoretical basis for education of different ages and education content, education of any age error, will cause obstacles to the development of a person's lifetime. He emphasizes family influence on individual personality development, reveal the special dynamic relationship between family and the individual personality development, and the formation of the individual personality and family interaction development model, implementing personality education to the family brings important enlightenment.

\begin{tabular}{|c|c|c|c|c|c|c|}
\hline $\begin{array}{l}\text { Infant early stage } \\
\text { (0-1.5 years old })\end{array}$ & $\Rightarrow$ & $\begin{array}{l}\text { Infant late stage } \\
\text { (1.5-3 years old) }\end{array}$ & $\Rightarrow$ & $\begin{array}{l}\text { Early childhood } \\
\text { (3-6 years old) }\end{array}$ & $\Rightarrow$ & $\begin{array}{c}\text { Childhood } \\
\text { (6-12 years old) }\end{array}$ \\
\hline & & & & & & \\
\hline $\begin{array}{c}\text { Late adulthood } \\
\text { (Over } 65 \text { years old) }\end{array}$ & 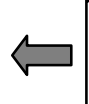 & $\begin{array}{l}\text { Middle adulthood } \\
\text { (25-65 years old) }\end{array}$ & & $\begin{array}{c}\text { Early adulthood } \\
\text { (18-25 years old) }\end{array}$ & & $\begin{array}{c}\text { Adolescence } \\
\text { (12-18 years old) }\end{array}$ \\
\hline
\end{tabular}

Fig. 3. Eight stage theory of personality development of E. H. Erikson

\section{Enlightenments of Personality Development Theory to the Children's Education}

Through the deep research in the theory of personality development, combined with years of experience in education practice, with reference to relevant research results, it is concluded that the theory of personality development of children education enlightenment is as follows:

(1) Children in all ages have different education. Session with Sigmund Freud believed that children's each development stage has its development tasks, only the phase of the mission can smoothly into the next stage of development. As long as the understanding of the features of the child in each growth stage and the education, education children can become very simple and easy.0 and 1 year old, the child's development task is to gain trust and overcome the mistrust, experience the realization of hope. Give the child enough love, and meet the basic needs of the children. Parents again busy, also to pay attention to and meet the child's physical and psychological needs; 2-3 years of age, children's development task is to obtain autonomy, overcome shyness and confused feeling, experiencing the realization of the "will". Help children to develop the ability of independent life, parents can't miss a good time to let go and regulations behavior, patiently guide children learn to do what thing; 4 to 6 years of age, children's development task is to obtain the initiative, to overcome the feeling of guilt, experiencing the realization of the "purpose". Create opportunities for children to develop initiative, let the child to participate in a variety of indoor and outdoor activities, develop hobbies, encouraging the spirit of active exploration;7 to 12 years old, the child's task is to get hard feeling and overcome the inferiority, the realization of "ability" to experience. Help your child get hard feeling, develop the ability to solve the problem, insist that children manage their at home, get into the habit of initiative to help do the housework.

(2) Children's education eventually point is "self-identity". "Self-identity" is the most important core in Erikson's personality theory and one of the most distinctive concept, refers to a person of the same in the past, present and future of the existence of the air self-consistency and continuity of subjective sensation or consciousness. Adolescent identity personification, refers to the needs of the teenagers, emotion, ability and goals and values characteristics such as integrated framework for unified personality, with a self-consistent emotion and attitude, needs and abilities of transfixion, the constant goal and faith. The establishment of self-identity, means that the individual and their own have a full understanding, to the past, present and future of self, combined into an organic whole, to establish their own ideals and values, and make themselves for the future development thinking. First, by showing the diversity of social culture, family provide children with a kind of can enhance the reserves of self-consistency and continuity; Second, the realization of the family to usurp the role of a series of action for children to provide a strong guarantee. As function is 
psychoanalytic theory to realize one person with another person has one of the earliest forms of emotional connection. Identity is changing at various stages before puberty, and determines the stages after puberty development, is the core of personality development structure, become the final point to children's personality education.

(3) The harmonious family atmosphere conducive to the healthy growth of children. Family atmosphere is the relationship between family members and build the interpersonal situation and atmosphere, to family members' mental and psychological plays an important role, is an important environmental factor of family life and grow. For children, the family is the primary environmental factor, so the family atmosphere plays an important role in children's growing, determines the children's psychological quality and personality development. Specific role embodies in four aspects: one is that good emotional psychological atmosphere conducive to children's mental health, harmonious family can give children a sense of security, to satisfy the children a sense of belonging, enhance children self-esteem and self-confidence, make the child get support; Second, a good cultural atmosphere to cultivate children's study habits, family culture background a subtle impact on children, encouraged kids to establish love the idea of knowledge, and gradually form the good habit of exploring the unknown and active learning; Three is that good democratic atmosphere conducive to shape children's independent personality, in an atmosphere of democracy and freedom, to children's equal opportunity for communication and self-independent, let children release their individuality and creativity, create a complete independent personality; Four is, good moral atmosphere conducive to cultivate children's moral behavior, carry out talking about moral and guidance, let children produce preliminary moral concept and moral consciousness, according to the teaching of the parents to correct, the moral behavior of specification itself.

(4) Mother plays an important role in children's education. Mother in the understanding of the child from the womb to start, anyone can't be like a mother to understand children's external environment, it is impossible to have deep confidence to the child's every move. Long live together form a sense of mother and son and mother complex, is the inseparable link between mother and child, and irreplaceable responsibility between mother and child, let mother more than anyone can timely grasp the child's idea. The role of mother to child education mainly embodies in four aspects: One is that the mother is the closest person with children, mothers all actions and emotions exerts a subtle influence on the children; The second is, the mother bear the heavy burden of child education first, say to the children of linguistic, cognitive, sensory, character, habits, such as training and education; Three is, my mother is a good example of child behavior, and behavior of the supervisor, in contact with the child, should attach great importance to the behavior of family members, remind children, lead to the direction of good healthy growth; A mother's love is the child grow the catalyst, a mother's love can help children to establish good psychological quality, to overcome the fear and anxiety, let the children learn to tolerance, patience and understanding. Family education as the starting point of life education and the basis points, mother shoulder the important task of education, for children's happy life to lay a solid foundation.

(5) Father is indispensable role in the process of children's education. Father in child personality forming and shaping behavior, plays a very important role in particular. Men generally has rich practice, open-minded and strong personality strengths, this is an advantage to the child. Father's love for children not only embodies in the material, more want to reflect on the spirit and action. Father effects on children's education is mainly embodied in three aspects: one is, conducive to social development, the father loves the show the bold and unconstrained, emotional wealth of society, from his father can get normal personality development;, 2 it is, be helpful for children to become a research shows that children brought up by men, higher IQ, will get better grades at school, are more likely to succeed in society. His father in terms of education child, have stronger purpose. In the aspect of training habits can education more children to be independent and decisive, have brave spirit and the spirit of adventure; Three is conducive to the healthy development of the gender, in communication and the boy will look at the boy with his own behaviors and to learn to take responsibility, the boy will be better from dad there observation and imitation of men's language behavior; In communication and daughter, also can make the daughter grew up access to a 
good male role models, distinguish the difference between men and women, to cultivate female temperament, will also be affected by the father's adventure, enterprising and independence.

(6) Reward and punishment is a powerful means to promote the development of children. Reward or punishment, are formed behavior means, is to regulate the behavior of children. "Reward" is to praise and encourage the children, in addition to understand children, want to the child. Education more effective than punishment reward, the reward is education for children's behavior as a result, to strengthen the child's behavior; Is to reward children's behavior process, in order to stimulate a child's interest and motivation; Create the environment, to indicate the child development direction; Appropriate to remind, enhance the child's psychological experience, the correct way of education children's bad behavior. Education should be accompanied by the phenomena of punishment in violation of ethics in, is also essential. Using punishment should pay attention to four points: first, to say the "degree", according to the behavior and cognition to punish, can light nor abuse punishment, grasp key point; Second, for the mistakes, not to get involved and rehash; Third, firmly attitude to be clearly pointed out that this kind of behavior is resolute don't; Fourth, not "hostility" and not with their own anger and blame, for children to vent their emotions. Anyhow, reward and punish children to grasp the specific method, right to education of children, gradually cultivate their noble moral character, let children to develop good character is one of the most important.

\section{Acknowledgement}

This work is supported by Liaoning provincial federation social sciences circles (2017lslktyb-007): Children's personality development and promotion strategies in the perspective of shadow education; Teaching reform of Bohai university (BDJG-15-YB-B-001): Exploration of performance evaluation model based on rotation classroom; Education science planning of Liaoning province (JG15CB167): Action research on integration of sensory integration training into children's sports activities.

\section{References}

[1] J. G. Dan, J. F. Zhang, "A review of western personality development theory," Legal System and Society, vol. 18, no. 4, pp. 225-226, 2009.

[2] M. L. Liu, H. Chen, "On Freud's theory of personality development and Its Enlightenment to the education of children," Science of Social Psychology, vol. 26, no. z1, pp. 59-62, 2011.

[3] Jing Han Education, "Mother's education plays an important role in children's life," http://www.zgjhjy.com/Html/news/jzyd/21064.shtml, 2016-10-8.

[4] H. Y. Hao, "Enlightenment of Erickson's Personality Development Theory to Family Personal Education," Academic Journal (Social Science Edition), vol. 21, no. 4, pp. 122-125, 2008.

[5] NetEase Parenting, "Father's 7 major role in the growth of children," http://baby.163.com/16/0608/02/BP0M6R8A00364O9M.html, 2016-10-8.

[6] S. A. Wang, N. W. Wang, "The influence of good family environment on children's healthy growth," Journal of Educational Development,, vol. 27, no. 1, pp. 53-54, 2009.

[7] Y. Chen, "On the positive significance of good family atmosphere in children's development," 才智, vol. 13, no. 32, pp. 286-287, 2012.

[8] 360 personal library, "On the reward and punishment system in family education," http://www.360doc.com/content/12/1020/22/9295247_242684355.shtml, 2016-10-8.

[9] Sina blog, "Children's education at different stages," http://blog.sina.com.cn/s/blog_9869b52d0102vvh4.html, 2016-10-8.

[10] X. L. Zhang, "The Enlightenment of Piaget's theory of moral development of children to children's rule Education," Journal of Ningde Normal University (Philosophy and Social Sciences), vol. 28, no. 4, pp. 104-106, 2009. 